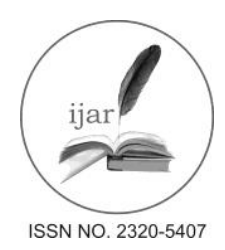

\section{Journal homepage:http://www.journalijar.com Journal DOI:10.21474/IJAR01}

REVIEW ARTICLE

\title{
RAPID SPREADING OF ZIKA VIRUS: THECHALLENGE FOR HUMAN HEALTH.
}

\author{
Taj Mohammad $^{1 *}$, Md. Tanjim Alam ${ }^{2}$, Nisha Chaudhary $^{1}$, Rafat Ali $^{1}$, Mahafooj Alee$^{2}$, Abdul Rahaman $^{3}$, \\ Ankita Kumari ${ }^{3}$, Md. Saddam H Ansari ${ }^{4}$. \\ 1. Department of Computer Science, Faculty of Natural Sciences, JamiaMilliaIslamia, New Delhi-110025, India. \\ 2. Department of Biosciences, Faculty of Natural Sciences, JamiaMilliaIslamia, New Delhi-110025, India. \\ 3. School of Studies in Biochemistry, Jiwaji University, Gwalior- 474011, M.P., India. \\ 4. School of Biotechnology, Jawaharlal Nehru University, New Delhi-110067, India.
}

\section{Manuscript Info}

\section{Manuscript History:}

Received: 11 April 2016

Final Accepted: 13 May 2016

Published Online: June 2016

Key words:

Zika Virus, rhesus monkey, Aedes mosquito, RNA genome, yellow fever, Guillian- Barre syndrome, amniotic fluid, Microcephaly.

*Corresponding Author

Taj Mohammad

\section{Abstract}

Today's world is constantly challenged by many diseases, which are characterized by many bacterial, viral or other microorganisms. However, many protective agents being already developed to inhibit and kill these microorganisms for complete cure. But nowadays there is a virus named Zikaa Flavivirus transmitted by Aedes mosquitoes, which has made a challenge to the scientists who are working in the field of Virology.The Pan American Health Organization (PAHO) issued an alert reflecting the confirmation of the first Zika virus (ZIKV) infection in Brazil. Nowadays, the spreading of this emerging Zika virus is ongoing globally and making a body of challenge for the universe. In this review, we discussed the current understanding of its transmission, epidemiology and clinical aspects regarding to the diseases caused by Zika virus.

\section{Introduction}

Zika virus (ZIKV) is an emerging single stranded RNAFlavivirusbelonging to the family of Flaviviradae and genus Flavivirus, same as the dengue virus ${ }^{[8]}$. The Flavivirus covers so many viral species such as yellow fever, dengue, Saint Louis encephalitis and West Nile viruses etc ${ }^{[17]}$. The Zika virus is spread by Aedes mosquito mainly Aedesaegypti and Aedesalbopictus particularly in the day time because this virus is very much active in day time ${ }^{[1,2,3,5]}$. This virus is enveloped, icosahedral and has a non-segmented single stranded positive RNA genome ${ }^{[8]}$. So it can directly be translated into viral proteins ${ }^{[8]}$. The infection shown as Zika fever, these are dengue, yellow fever, Guillian-Barre syndrome and Japanese encephalitis etc ${ }^{[2]}$.

\section{Epidemiology}

Zika virus was first isolated from the serum of rhesus monkey in 1947 from the Zika forest of Uganda ${ }^{[1,2,6]}$; simultaneously it has been spread to different places in the world. It was first identified in human in 1952 in Uganda and Tanzania ${ }^{[1]}$. There were several cases issued throughout the decade.

Investigations have been revealed that Brazil, some part of Mexico and Caribbean Iceland's severely affected by this virus ${ }^{[1]}$. Zika virus also spread to some other places like North America, French Polynesia, Africa and some parts of South Asia ${ }^{[1]}$. In 2015 in Brazil there were near about 2500 patients found who wasseverely affected by this virus ${ }^{[5]}$. Though there are not enough cases found in Asia like Brazil, but scientists even think that this virus has taken place in those areas ${ }^{[5]}$. The World Health Organization (WHO), Pan American Health Organization (PAHO) and other agencies has been already issuednotice about Zika virus and associated disorders, worldwide.

\section{Studying the Zika virus}

In the recent years the studies of Zika virus has gained the heights because of its emergingpersonality and its association with various neurological and the other rare diseases globally. 
So, the various aspects of advance sciences have been used to investigate the ZIKV. Currently the atomic structure of Zika virus has been revealed by the use ofCryo-electron microscopy ${ }^{[18]}$. The structural information for ZIKV through such advance and helpful technology would give up some fruitful outcomes over disease control in order to modernize the basic medicinal field for human welfare and development of biological research.
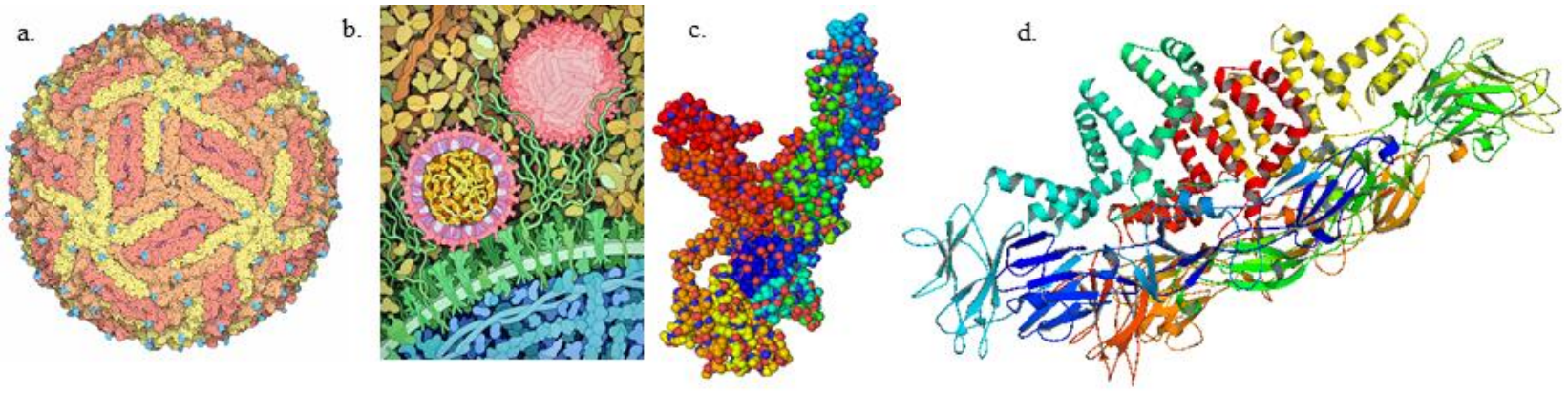

Figure 1:a. The Cryo-EM structure of Zika Virus ${ }^{[18]}$ : Molecule of the month-May, 2016, PDB(Yellow and Red: envelope proteins with glycosylation in turquoise, Magenta: membrane protein), $\boldsymbol{b}$. ZIKV in cross section (center left) with envelope and membrane protein attached to a lipid membrane (light purple), Association of RNA genome (Yellow) with capsid proteins(Orange), the interaction of viruses with cell surface receptors (Green) and they are surrounded by blood plasma at the top ${ }^{[18]}$.c.Dot representation of envelope and membrane proteinsof ZIKV.d. Cartoon representation of Zika virus. ${ }^{\text {[Source: Protein Data Bank] }}$

\section{Transmission of Zika virus}

There are mainly two ways of transmission of Zika virus, the first is mosquito-borne transmission and another one is non-mosquito transmission ${ }^{[16]}$. In mosquito-borne transmission the Zika virus is transmitted to the human body through the bite of mosquitoes. Aedes genus mainly the female one requires blood in order to lay eggs hence these mosquitoes feeds on blood ${ }^{[9]}$. Primarily the ultimate host of the virus was monkey so its life cycle called as enzootic mosquito-monkey-mosquito cycle ${ }^{[8]}$.
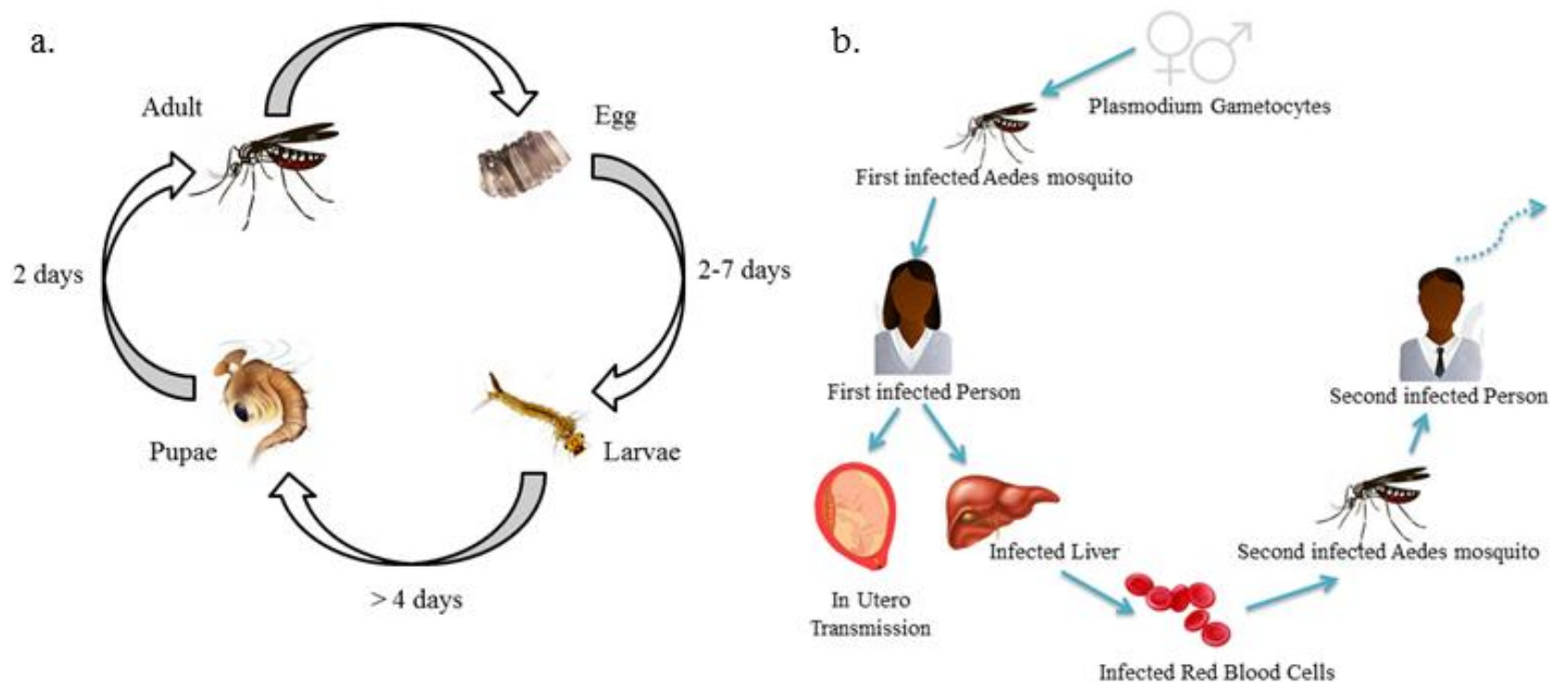

Figure 2: a. Life cycle of Aedes mosquito; b.Zika virus transmission cycle.

The virus is also transmitted through sexual contacts because this virus is capable to grow in serum of man for at least 2 to 10 weeks $^{[5,10,11]}$. There are several reports in the United States, which confirms that unprotected sexual intercourse also transmits this virus to a normal healthy individual ${ }^{[11,12]}$. If a person is infected with the Zika virus he should avoid sexual contact with his partner because this virus is much more sensitive in sexual transmission ${ }^{[8]}$. There is also a strong possibility that the Zika virus can be spread through blood transfusions ${ }^{[19]}$. Studies also 
revealed that if a person visited Zika virus affected areas he should also avoid sexual contact for at least six months or use condoms for any physical contact ${ }^{[13]}$.

This virus is severely affecting those females who are pregnant ${ }^{[3,5,14]}$. Because this virus can easily penetrate into the amniotic fluid of placenta, from there they can also transmit into the fetus ${ }^{[3,14]}$. A disease has been seen in the new born babies and Childs between 3 to 9 years old called Microcephaly in which the very small head is formed in comparison to the normal size ${ }^{[1,2,3,8,14]}$. Intelligence is reduced and shows other complications. According to the WHO, the Zika infection is subsequently associated with microcephaly and other neurological disorders. A new study has revealed that the Zika virus damages the human placental barrier ${ }^{[15]}$.They detected the viral RNA in placental tissues, amniotic fluid of newborn and fetal brain tissues.

\section{The spread of the Zika virus around the Globe}

As of February, 2016, the Zika virus has continued to spread into regions of the countries and territories where presence of ZIKV was indicated because; they can be spread globally into additional environments where the Aedescan live and breed ${ }^{[20]}$.

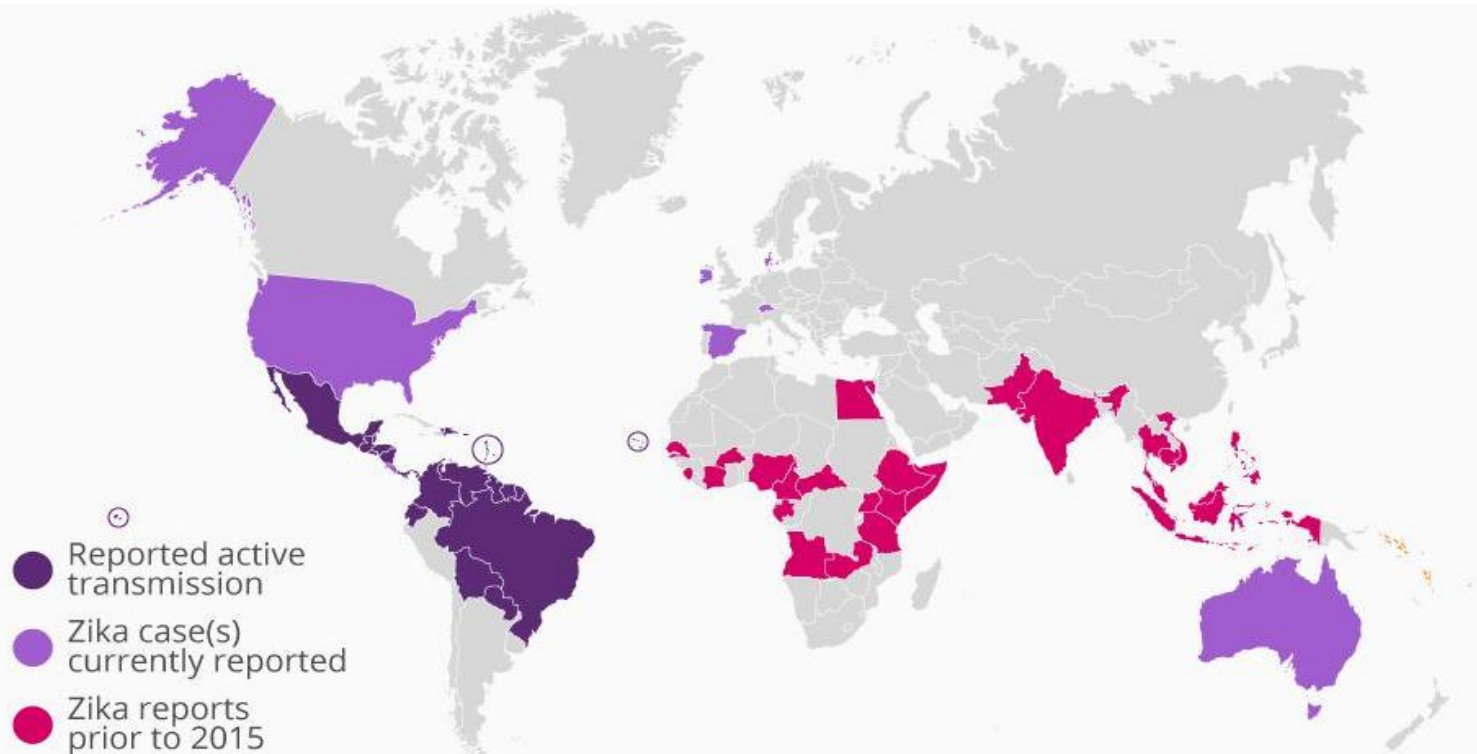

Figure 3: Countries and territories with active Zika virus transmission (as of February 2016)and reported cases. Source: Centers for Disease Control and Prevention.

\section{Symptoms}

Primarily, Zika infection have no symptoms, but the people may have some common symptoms of infections like headache, mild fever, sweating, vomiting, joints pain, muscle pain, malaise, conjunctivitis (pain in the back of the eyes, eye redness etc.) and rash on skin etc ${ }^{[2,3,4,5]}$. The symptoms may last from afew days to a week.

\section{Diagnosis}

There is some laboratory diagnostic approaches by which the diagnosis of the ZIKV can be realized by the detection of virus, viral nucleic acid, viral antigen, or virus specific immunoglobulin using various molecular techniques, such as conventional or real time reverse-transcriptase polymerase chain reaction (RT-PCR) ${ }^{[21]}$. In addition, the associated viral antigens and antibodies can also be detected in other tissues by immunohistochemistry and using various serological tests such as ELISA or immunofluorescence after a couple of days to a week of infection ${ }^{[22]}$.

\section{Preventions, control and treatments}

There are several preventions may be applied over Zika infection, including- avoiding traveling to the countries or places having Zika-affected areas,avoiding unprotected sexual contact with partners, especially with who are at risk for the infection of Zika virus, using bed nets for protecting sleeping, covering the skin with cloths, window screens to reduce the human contact with mosquito vector and using various vectorcontrol approaches such as insect repellent and eliminate standing water containers to prevent mosquito breeding sites. 
There is no vaccine, specific drug or any other prevention strategies for the treatment of Zika virus infection. However, for the relief, the patient should get plenty of bed rest and the use of liquids and fluidswith medicine is recommended to relieve pain and fever.

\section{Discussion}

The Zika virus has shown different changes with the change in different places in the world. The endemic change with mosquito infection caused many diseases like microcephaly, neurological disorders, Japanese encephalitis etc. In the future the virus infection can be spread through the increasing population of the Aedes genus mosquitos. The virus also transmitted person to person through physical contacts. This virus is much more challenged than any other virus like Ebola. This virus mainly affects the unborn, newborn and children with an age of 3 to 9 years. There is no medicine or therapeutic agents for killing or inhibiting the virus for complete cure. Perhaps the biggest challenge for human being with Zika to recognized it with different kind of diseases and applies proper medication.So there is an urgent need to effectively design of strategies and approaches to address these issues for the prevention and/or treatment of the Zika virus transmission and infection.

\section{Acknowledgement}

We, the Authors thank and greatly acknowledged to the respective departments, teachers and friends for their helpful discussion and support and encouraging for making such manuscript.

\section{References}

1. Kindhauser MK, Allen T, Frank V, Santhana RS \& Dye C. "Zika: the origin and spread of a mosquito-borne virus". Bull World Health Organ E-pub: 9 Feb 2016. doi: http://dx.doi.org/10.2471/BLT.16.171082

2. Malone RW, Homan J, Callahan MV, Glasspool-Malone J, Damodaran L, et al. (2016) "Zika Virus: Medical Countermeasure Development Challenges".PLoSNegl Trop Dis 10(3): e0004530. doi: 10.1371/journal.pntd.0004530

3. Hui-Lan Chen, Ren-Bin Tang. "Why Zika virus infection has become a public health concern?" Journal of the Chinese Medical Association 79 (2016) 174e178. doi:10.1016/j.jcma.2016.03.001

4. S Kutsuna, Y Kato, T Takasaki, M L Moi, A Kotaki, H Uemura, T Matono, Y Fujiya, M Mawatari, N Takeshita, K Hayakawa, S Kanagawa, N Ohmagari."Two cases of Zika fever imported from French Polynesia to Japan, December 2013 to January 2014"'.Euro Surveill. 2014 Jan 30; 19(4). pii: 20683

5. JyotiShelar. “Zika virus set to hit India?’Mumbai Mirror | Jan 27, 2016, 11.28 AM IST

6. Gavin PJ, Kazacos KR, Shulman ST. "Baylisascariasis" Clin. Microbiol. Rev. October 2005 vol. 18 no. $4703-$ 7181 October 2005. doi: 10.1128/CMR.18.4.703-718.2005

7. Malone, Robert W.; Homan, Jane; Callahan, Michael V.; et al. (2 March 2016). "Zika Virus: Medical Countermeasure Development Challenges". PLOS Neglected Tropical Diseases $10 \quad$ (3): e0004530.doi:10.1371/journal.pntd.0004530

8. Rasmussen, Sonja A.; Jamieson, Denise J.; Honein, Margaret A.; Petersen, Lyle R. (13 April 2016). "Zika Virus and Birth Defects- Reviewing the Evidence for Causality". New England Journal of Medicine. doi:10.1056/NEJMsr1604338

9. "Dengue and the Aedesaegypti mosquito",Centers for Disease Control and Prevention, Dengue Branch, San Juan, PR, 2 February 2012, 2 pages.http://www.cdc.gov/dengue/resources/30Jan2012/aegyptifactsheet.pdf

10. Alexandra M. Oster, John T. Brooks, Jo Ellen Stryker, et al. "Interim Guidelines for Prevention of Sexual Transmission of Zika Virus — United States, 2016", Morbidity and Mortality Weekly Report 2016;65(Early Release 5 February 2016): 1-2

11. Musso, Didier; Roche, Claudine; Robin, Emilie; et al. (February 2015). "Potential Sexual Transmission of Zika Virus". Emerging Infectious Diseases 21(2): 359-361. doi:10.3201/eid2102.141363

12. Foy, B. D., Kobylinski, K. C., Foy, J. L. C., Blitvich, B. J., Travassos da Rosa, A., Haddow, A. D.,Tesh, R. B. (2011). "Probable Non-Vector-borne Transmission of Zika Virus, Colorado, USA. Emerging Infectious Diseases". 17(5), 880-882. http://doi.org/10.3201/eid1705.101939

13. Petersen, Emily E.; Polen, Kara N.D.; Meaney-Delman, Dana; et al. (25 March 2016). "Update: Interim Guidance for Health Care Providers Caring for Women of Reproductive Age with Possible Zika Virus Exposure - United States, 2016". MMWR. Morbidity and Mortality Weekly Report 65(12). doi:10.15585/mmwr.mm6512e2er

14. Schuler-Faccini L, Ribeiro EM, Feitosa IM, Horovitz DD, Cavalcanti DP, Pessoa A, Doriqui MJ, Neri JI, Neto JM, Wanderley HY, Cernach M, El-Husny AS, Pone MV, Serao CL, Sanseverino MT (2016). "Possible 
Association between Zika Virus Infection and Microcephaly -Brazil, 2015”. MMWR Morb. Mortal. Wkly. Rep. 65 (3): 59-62. doi:10.15585/mmwr.mm6503e2

15. Noronha Lucia de, ZanlucaCamila, Azevedo Marina Luize Viola, LuzKleber Giovanni, \& Santos Claudia Nunes Duarte dos. (2016). "Zika virus damages the human placental barrier and presents marked fetal neurotropism". Memórias do InstitutoOswaldo Cruz, 111(5), 287-293. Epub April 29, 2016

16. Lyle R. Petersen, M.D., M.P.H., Denise J. Jamieson, M.D., M.P.H., Ann M. Powers, Ph.D., and Margaret A. Honein, Ph.D., M.P.H. "Zika Virus", $N$ Engl J Med 2016; 374:1552-1563April 21, 2016DOI: 10.1056/NEJMra1602113

17. CamilaZanluca, Claudia Nunes Duarte dos Santos. "Zika virus- an overview". Microbes and Infection 18 (2016) $295 \mathrm{e} 301$

18. DevikaSirohi, Zhenguo Chen, Lei Sun, Thomas Klose, Theodore C. Pierson,Michael G. Rossmann, Richard J. Kuhn "The 3.8 Å resolution cryo-EM structure of Zika virus". Science 22 Apr 2016: Vol. 352, Issue 6284, pp. 467-470 DOI: 10.1126/science.aaf5316

19. "Zika and Blood Transfusion". Centers for Disease Control and Prevention. http://www.cdc.gov/zika/pdfs/zikakey-messages.pdf

20. European Centre for Disease Prevention and Control. Epidemiological update: Outbreaks of Zika virus and complications potentially linked to the Zika virus infection. Last updated: February 5, 2016, ECDC Website, http://ecdc.europa.eu/_layouts/forms/News_DispForm.aspx?ID=1353 (Accessed 12.02.2016).

21. R.S. Lanciotti, O.L. Kosoy, J.J. Laven, J.O. Velez, A.J. Lambert, A.J. Johnson, et al.Genetic and serologic properties of Zika virus associated with an epidemic, Yap state, Micronesia, 2007Emerg Infect Dis, 14 (2008), pp. 1232-1239

22. R.B. Martines, J. Bhatnagar, M.K. Keating, L. Silva-Flannery, A. Muehlenbachs, J. Gary, et al. Evidence of Zika virus infection in brain and placental tissues from two congenitally infected newborns and two fetal losses - Brazil, 2015 Morb Mortal Wkly Rep, 65 (2016), pp. 1-2. 